\title{
Escritura, Pensamiento y Lenguaje: Consideraciones acerca de una Ética literaria y/o filosófica según Habermas y Derrida
}

\section{Writing, Thought, and Language: Literary and/or Philosophical Ethics According to Habermas and Derrida}

\author{
Mario Villalobos Kirmayr \\ Universidad Santo Tomás de Chile
}

(Recepción: Marzo 2005 - Aceptación: Octubre: 2005)

\begin{abstract}
El proyecto filosófico implicado en la deconstrucción derrideana trae como una de sus consecuencias la desdiferenciación entre filosofía y literatura. Esto, según Habermas, depotencia el discurso filosófico no solo en términos epistemológicos sino que también, y muy sensiblemente, en términos ético-normativos. La discusión literatura/filosofia se enmarca por tanto en la más amplia problemática acerca de la legitimidad del carácter pretendidamente universalista del discurso filosófico. En este contexto, se revisan algunas de las principales críticas formuladas por Habermas en contra de la estrategia deconstruccionista de Derrida.

Palabras clave: Deconstrucción, lenguaje, ética.
\end{abstract}

\begin{abstract}
A consequence of Derridean deconstructionist philosophy is the dedifferentiation between philosophy and literature. According to Habermas, this debilitates philosophical discourse not only in epistemological terms, but also, and very markedly, in ethical-normative terms. The literary/philosophical discussion, then, takes place in the broader context of the polemic of the legitimacy of the supposed universalism of philosophical discourse. In this context, we review some of Habermas's main criticisms of Derrida's deconstructionist strategy. Key words: Deconstruction, language, ethics
\end{abstract}

Se nos pide comenzar una reflexión acerca de la filosofia considerando el hecho - a primera vista del todo trivial- de que ella se escribe. Por cierto que sí, concedemos complacientes, así como se escribe cualquier idea o cosa que uno quiera registrar. Mas, de esta observación, agregamos, no se ve en principio qué cosa importante o esencial podríamos desprender respecto de la filosofía, cuyo ámbito natural es el del pensamiento. Se escribe simplemente para dejar testimonio de lo que se ha pensado, como una forma accesoria de fijar materialmente ideas y razonamientos. Luego, observar que la filosofía se nos dé como escritura estaría señalando un hecho a lo más meramente instrumental, pues se puede filosofar sin escritura, mas no se puede escribir filosofia sin un previo filosofar. Y por lo demás, rematamos con autoridad, el mismo padre de la filosofía occidental sabemos no escribió una sola palabra.

Hasta ahí nuestro sentido común victorioso, pero se nos insiste a continuación atender a la siguiente pregunta; si es tan trivial o meramente instrumental el hecho de que la filosofia se escriba, ¿por qué ella misma se ha esforzado

* Licenciado en Psicología, Pontificia Universidad Católica de Chile. Magíster (c) en Filosofía mención Epistemología, Universidad de Chile. E-mail: mariovilobos@hotmail.com tanto en hacer ver que la escritura le es algo totalmente inesencial?, ¿por qué si la filosofia, en tanto institución, no se nos ofrece a fin de cuentas sino como escritura, ella misma no ha querido nunca históricamente reconocer tal cosa de sí?, ¿por qué Platón y otras tantas cumbres filosóficas se han dado el trabajo de levantar todo tipo de condenas contra la escritura, como si de un veneno mortal se tratara?

Nos quedamos pensando por un momento en silencio y, con algo de perplejidad, reparamos de pronto en un detalle sobre el cual hasta ahora, ahora que se nos está planteando este extraño asunto, no habíamos puesto nunca la menor atención. ¿No es cierto que Sócrates, el mismísimo 'padre' al que hemos aludido y que sabemos no escribió palabra alguna, encontró el mensaje filosófico central de su doctrina como inscripción y no como oralidad? "Conócete a tí mismo" es una frase que Sócrates lee inscrita en la gruta de Delfos, pero que no escucha de voz alguna. ¡Vaya!, y una pequeña agitación pareciera perturbar ahora nuestro apacible sentido común.

Esta trivial observación, convertida de pronto en asombro, es precisamente la pregunta que Jaques Derrida ha enarbolado a la vez como sospecha y programa filosófico, dejando deslizar provocativamente la idea de que tal vez la 
filosofia no ha sido sino un antiquísimo juego literario-escritural de Occidente, cuyos jugadores, llamados filósofos, no han querido nunca verse a sí mismos ni ante los demás como - ¿simples?- literatos o escribanos.

Como tendremos ocasión de ver en este artículo, la problematización que Derrida introduce con respecto a la escritura y el lenguaje filosófico, traerá como consecuencia la indistinción o disolución de los límites entre filosofia y literatura. Disolución que, de tener sentido, mucho más allá de acarrearnos algunos problemas de ordenamiento bibliotecario, nos comprometería con profundos problemas no sólo epistemológicos, sino que también éticos y políticos. Al menos esto último es algo que Jürgen Habermas tendría bastante claro, pues desde su consabida posición de bastión del proyecto ilustrado no demorará en lanzar con fuerza sus críticas ante las pretendidas estrategias disolutivas de Derrida, saliendo una vez más en defensa de la racionalidad y legitimidad normativa de todo discurso filosófico que se precie de tal.

\section{Derrida: represión de la escritura y deconstrucción}

Denunciar la represión que ha sufrido la escritura por parte de la filosofía occidental en su conjunto, es una de las tareas a las que Derrida ha consagrado mayor empeño intelectual. Replicada en múltiples pares jerárquicos caros a la tradición filosófica (alma/cuerpo, ideal/material, original/copia, significado/significante), la dominación de la voz (phoné) por sobre la escritura (gramma) revela para Derrida un lugar filosófico eminente en el que se puede descubrir la violencia encarnada de la metafisica de la presencia. Instalado ya en la era de la filosofía del lenguaje, Derrida lleva a cabo en este terreno una crítica similar a la que Nietzsche en su momento formulara frente a la totalidad de la metafísica y cultura occidentales, bien que con estrategias y entradas esta vez bastante novedosas. Precisamente la de la represión de la escritura, es una de esas entradas que han hecho de Derrida una figura de resonantes repercusiones filosóficas, y que lo han instalado también como principal precursor de las corrientes deconstruccionistas en el ámbito de la crítica literaria norteamericana.

Para persuadirnos de que la filosofía y el pensamiento occidental en general efectivamen- te han operado como represión de la escritura, Derrida se da el trabajo de rastrear en Platón, Rousseau, de Saussure, y Husserl, entre otros, los elementos a veces casi imperceptibles de esta jerarquización. ${ }^{1}$ Sobre todo en Rousseau, a quien dedica notables análisis que muestran cómo en el discurso de este autor la escritura es relegada y condenada en términos filosóficos no obstante, o precisamente por ello, se la contempla como un peligro mortal de corrupción. "Tal es la situación de la escritura dentro de la historia de la metafísica: tema rebajado, (...) reprimido, desplazado, pero que ejerce una presión permanente y obsesiva desde el lugar donde queda contenido. Se trata de raspar una escritura temida porque ella misma tacha la presencia de lo propio dentro del habla". ${ }^{2}$ Derrida denuncia por esta vía la postergación de la marca material del signo, de la sensibilidad, y reformula a través de este elaboradísimo expediente semiótico la crítica furibunda que otrora lanzara Nietzsche contra todas las formas de platonismo occidental.

Pero no sólo se remite Derrida a mostrar esta represión, sino que también y con cierto tono profético señala el advenimiento, merced a la propia lógica interna del lenguaje, de su singular emancipación. "Por una necesidad casi imperceptible, todo sucede como si, dejando de designar una forma particular, derivada, auxiliar, del lenguaje en general (...), el concepto de escritura comenzara a desbordar la extensión del lenguaje". ${ }^{3} \mathrm{O}$ expresado en otra de las fórmulas derrideanas, estaríamos presenciando "el fin del libro y el comienzo de la escritura" ${ }^{4}$ En efecto, se trata aquí de una escritura que no se identifica con la escritura fonética occidental, aquella que sigue la articulación de la voz, sino de una archiescritura entendida como condición de posibilidad de todo lenguaje hablado, escrito o actuado. La escritura, como significante del significante, describiría y se nos revelaría como lo que el lenguaje mismo es y ha sido desde su origen; un juego de referencias significantes. "El advenimiento de la escritura es el advenimiento del juego"s, en cuanto el juego se afirma sobre

1 Para una exposición orgánica de este cometido, ver Derrida, J. De la Gramatología, Madrid: Siglo XXI editores, 1971.

2 Derrida, J. De la Gramatología, Madrid: Siglo XXI editores, 1971, pp. 338-339.

3 Derrida, J., De la Gramatología, Madrid: Siglo XXI editores, 1971, pp. 11-12.

4 Ibíd. p. 11.

5 Ibíd. p. 12. 
sí mismo y tiende así a borrar la distinción entre el adentro y el afuera del lenguaje, que es primordialmente escritura.

Con este y otros gestos polémicos Derrida se instala y perfila entonces en su propia lucha, con su propio gigante a combatir y sus propias armas. El logofonocentrismo, la metafísica de la presencia, son la estructura misma que superdetermina entonces el conjunto todo del pensamiento y las prácticas de Occidente. La tradición metafísica occidental determina desde sus categorías centrales la vida y organización del hombre, su comprensión del mundo, su autocomprensión, y la noción misma de mundo. La labor filosófica es la deconstrucción (des-sedimentación, solicitación) de esta estructura con el fin de mostrar cómo en lo reprimido (lo accidental, lo contingente, lo suplementario) y pretendidamente prescindible habita precisamente la condición de posibilidad de aquello que la tradición metafísica supone como incondicionado y fundante.

Hemos dicho deconstrucción, y hemos de advertir antes que todo que para Derrida la deconstrucción no es ni una nueva metodología filosófica (o hermenéutica), ni un conjunto de reglas o técnicas procedimentales de crítica y análisis literario. Ella no pretende agotarse -ni mucho menos- en meras consideraciones formales, pues su ejercicio estaría implicando más bien:

...una toma de posición (...) en base a las estructuras político-institucionales que forman y regulan nuestra actividad y nuestras competencias. Precisamente porque no concierne tan sólo a los contenidos de sentido, la deconstrucción no puede ser escindida de esta problemática político-institucional y requiere un nuevo planteamiento sobre la responsabilidad, un planteamiento que no confía ya en los códigos heredados de lo político y lo ético. (...) La deconstrucción no se limita ni a una reforma metodológica sustentadora de la organización dada, ni inversamente a una parodia de destrucción irresponsable o irresponsabilizante que tendría como más seguro efecto el dejar todo como está... ${ }^{6}$

Como señala Peñalver, la deconstrucción se ha ofrecido desde temprano como algo más que un mero discursso teórico que se ejercita y compla-

6 Derrida, J., La filosofía como institución. Barcelona: Granica, 1984. Citado en "La deconstrucción: escritura y filosofia”, Peñalver, P., Barcelona: Montesinos, 1990, p. 17. ce en destituir a sus similares. Lo por deconstruir aquí no es por sí mismo cierto orden conceptual o forma de pensamiento, sino más bien cierta organización práctica social e histórica que se ha plasmado bajo su figura. A juicio de Peñalver, no es pertinente tildar por tanto a esta empresa deconstructiva como una presunta despolitización del discurso, por más que ella sea también entre otras cosas un intento de deconstrucción de la filosofia crítica 'tradicional'. Derrida mismo reconoce el infortunio de la palabra 'deconstrucción' por cuanto su prefijo negativo evocaría tendenciosamente tan sólo la idea de demolición, nihilismo y destrucción, ocultando el carácter afirmativo que acompaña a este pensamiento. ${ }^{?}$

Aunque la obra de Derrida pueda ser tomada en conjunto con la de sus contemporáneos franceses (Foucault, Deleuze, Lyotard) bajo una denominación tan general y laxa como la de postestructuralismo o teoría posmoderna, en tanto todos ellos suceden históricamente al estructuralismo y asumen como base la crítica nietzscheana al conjunto de la filosofia de Occidente, no es menos cierto que tampoco se la puede asimilar sin más a una corriente general del pensamiento francés. Según Peñalver, la especificidad de la deconstrucción vendría dada por el interés sistemático que muestra en el orden conceptual y el cuerpo textual de la historia de la filosofía. Este acercamiento sistemático al conjunto del pensamiento filosófico de Occidente sería aquello que mantiene a Derrida en un permanente reenvío crítico hacia la meditación de Heidegger respecto de la ontoteología y el olvido del ser en la metafísica. ${ }^{8} \mathrm{Y}$ aunque Peñalver quiere advertir en este punto que no por ello ha de entenderse la deconstrucción como una 'continuación' de Heidegger, veremos luego que es precisamente allí donde Habermas apuntalará su crítica a la propuesta derrideana, a la cual catalogará violentamente como un mero "sobrepujamiento de la filosofia [heideggeriana]"."

7 Para un comentario acerca de la fortuna de la noción de deconstrucción, ver la "Carta a un amigo japonés", en Derrida, J., El tiempo de una tesis, Barcelona: Proyecto A Ediciones, 1997, pp. 23-27.

8 Peñalver, P., La deconstrucción: escritura y filosofia, Barcelona: Montesinos, 1990, pp. 20-21.

9 Habermas, J., El discurso filosófico de la Modernidad. Madrid: Taurus, 1989. Puesto que en la lección anterior Habermas ha declarado a Heidegger como sucumbiendo en una 'filosofia primera (del origen) fluidificada en tiempo', la deconstrucción derrideana recibe el aparatoso remate de 'sobrepujamiento de la filosofia primera temporalizada'. 
Otra apreciación bien distinta es la que ofrece Callinicos ${ }^{10}$, quien, siguiendo a Rorty, entiende la especificidad de Derrida en el 'textualismo' que encierra esta versión del postestructuralismo, cuya célebre consigna "no hay fuera de texto" implicaría la imposibilidad de escapar de lo propiamente discursivo. El textualismo vendría siendo, según Callinicos, tan sólo otra forma de enredarse en las aporías del irrealismo. A esta versión derrideana Callinicos opone la de Foucault, cuyo pensamiento lograría articular 'lo dicho y lo no dicho' escapando así al encierro intralingüístico del textualismo. En todo caso, y ciñéndonos a los propósitos específicos de este artículo, dejaremos para más adelante la crítica del 'textualismo' derrideano a cargo del propio Habermas.

Más allá de las múltiples querellas que en paralelo se van suscitando entre detractores y seguidores de la obra derrideana, conviene que avancemos hacia aquella zona polémica en que Derrida ejercita la deconstrucción de los límites entre filosofía y literatura. Para ello tal vez sea útil remitirse a las mismas palabras de Derrida cuando es consultado acerca del tema: "En principio mi deseo iba por el lado en que el acontecimiento literario atraviesa y desborda incluso la filosofía (...) Para analizar la interpretación tradicional de la escritura, su conexión esencial con la esencia de la filosofía, de la cultura e incluso del pensamiento político occidentales, era necesario no encerrarse ni en la filosofia como tal..."." Precisamente la represión sistemática de la escritura que ha operado la metafísica a lo largo de su extensa historia tendría que ver con la conjura de este peligro que se cierne sobre todo lo escrito; la retoricidad inextirpable del 'modo en que son (ex) puestas las ideas'. Los puntos de apoyo para esta tesis disolutiva de los límites de la literalidad de todo discurso, son por una parte Nietzsche y su crítica del concepto de verdad en sentido extramoral, y por otra la solicitación crítica de Paul Valéry hacia el discurso filosófico. Valéry es quien lúcidamente “...recuerda al filósofo que la filosofía se escribe. Y que el filósofo es filósofo en tanto lo olvida". ${ }^{2}$

${ }^{10}$ Callínicos, A., Contra el Postmodernismo: Una crítica marxista. Bogotá, Colombia: El Áncora Editores, 1993, pp. 136-138.

1 Entrevista con Christian Descamps, en Derrida, J., El tiempo de una tesis, Barcelona: Proyecto A Ediciones, 1997, p. 102.

12 Derrida, J., "Qual Cual. Las fuentes de Valéry" en Márgenes de la filosofia, Madrid: Cátedra, 1989, p. 331.
Cabe hacer notar que el movimiento de esta tesis es el de depotenciar la pretensión epistemológica del discurso que tradicionalmente se tiene por no literario (la historia, la teoría científica, la filosofía). Pues concediendo el hecho de que la literatura pertenece al reino de la ficción (y no al de lo real), la sospecha que en esta tesis se despliega es aquella que cuestiona no la condición de este rasgo ficcional, cuanto la exclusividad que se le asigna celosamente para con lo estrictamente 'literario'. A fin de cuentas, si 'no hay fuera de texto', si no es posible justificar la correspondencia entre lenguaje y mundo extralingüístico, si no hay cómo anclar las palabras con las cosas, porque las cosas mismas y el mundo no aparecen sino en aquello que los nombra, ¿cómo pretender que exista algo así como un discurso verdadero?, ¿cómo distinguir entre aquello que es ficción y aquello que no? ${ }^{13} \mathrm{Si}$ esto fuese así, si todo discurso es ineluctablemente construcción ficcional, ¿cómo cabe leer entonces aquellos discursos que pretenden ser discursos única y puramente veritativoasertóricos? Derrida señala explícitamente la estrategia a seguir: “...estudiar el texto filosófico en su estructura formal, en su organización retórica, en la especificidad y diversidad de sus tipos textuales, en sus modelos de exposición y de producción -más allá de lo que se llamaba en otros tiempos los géneros- (...) En breve, considerar también la filosofía como un 'género literario particular', que bebe de la reserva de una lengua, que dispone, fuerza o aparta un conjunto de recursos trópicos más viejos que la filosofía". ${ }^{14}$

Toda esta maniobra deconstruccionista trae como consecuencia el tener que admitir que ningún discurso es verdadero, pues la verdad sería una noción ficticia a la que 'en realidad' ningún discurso podría aspirar sensatamente. Solidariamente, la demarcación entre literario y no-literario se torna entonces problemática, pues ya definitivamente "la especificidad de los textos literarios con respecto a otros textos, lo que nuestros mayores llamaban la 'literariedad' (...) de la escritura, es hoy dudosa'. ${ }^{15}$

\footnotetext{
${ }_{13}$ Para el ejercicio de deconstrucción de la noción de verdad, ver Derrida, J., La tarjeta postal. De Freud a Lacan y más allá, México: Siglo XXI, 1986.

14 Derrida, J., "Qual Cual: Las fuentes de Valéry" en Márge nes de la filosofia, Madrid: Cátedra, 1989, pp. 333-334.

is Rojo, G., Diez tesis sobre la Crítica, Santiago: LOM Ediciones, 2001, p. 9. La cursiva es nuestra.
} 
La crítica de Habermas a la deconstrucción derrideana

\section{Radicalización del proyecto heideggeriano}

Según Habermas, Derrida se plantea a sí mismo como legítimo discípulo crítico y continuador del proyecto de Heidegger (el de la 'Carta sobre el humanismo'). Al igual que su maestro hiciera con la historia del Ser, Derrida encara el conjunto todo de Occidente y lo confronta con su otro (sus categorías excluidas, sus nociones suprimidas o subordinadas), señalando al mismo tiempo el final del pensamiento antropocéntrico y el fin de la autocomprensión humanística del hombre. La crítica heideggeriana a la metafísica en tanto filosofía centrada en el sujeto, tomará en Derrida el novedoso expediente de crítica al logofonocentrismo en términos de solevantamiento de una archiescritura.

Pero Derrida -aprecia Habermas- toma también distancia de Heidegger y se aleja de la retórica fatalista de aquél para situarse ahora en una actitud mucho más subversiva y contestataria. Habermas se pregunta entonces si con este cambio de actitud o de tono, ha de registrarse también un cambio ostensible en el concepto heideggeriano de historia del Ser, o si no se trata más bien de una misma idea o tesis defendida esta vez tan sólo bajo otro temperamento discursivo. ${ }^{16}$

Los avances que Derrida alcanza con respecto a lo hecho por Heidegger en cuanto a crítica de la metafísica, los obtiene a partir del estructuralismo lingüístico que enmarca la atmósfera intelectual en que se forma. Ello le permite emprender desde Saussure una superación efectiva de la filosofia de la conciencia (Husserl), para situarse de lleno en el terreno del lenguaje. Pero su reflexión acerca del lenguaje, acusa certeramente Habermas, se desarrolla en una dimensión puramente semiótica. Más como una crítica a la fonética estructuralista ( $\mathrm{y}$ un intento de esclarecer los fundamentos de una ciencia de la escritura o Gramatología), que como una reflexión acerca de las condiciones de uso del lenguaje ordinario. Es decir, Habermas señala que la filosofía del lenguaje de Derrida discurre totalmente por fuera de la dimensión pragmática, y que con ello se cierra el camino hacia un entendimiento del lenguaje en su naturaleza

${ }^{16}$ Habermas, J., El discurso filosófico de la Modernidad. Madrid: Taurus, 1989, pp. 198-199. intersubjetiva y comunicativa. Este cierre traerá según Habermas los costes de no poder escapar finalmente a aquella filosofía que el proyecto deconstruccionista pretendía desmantelar: la filosofía del sujeto. Esto por cuanto la crítica que emprende contra Husserl, al estar cortada al talle del estructuralismo, terminará por levantar un nuevo dominio trascendental que, ya no siendo el de las esencias significativas sino esta vez el de los significantes (marcas, sustratos sígnicos materiales), aparecerá ahora como nueva condición de posibilidad de todo lenguaje y significado: la escritura.

La noción de escritura le sirve a Derrida para señalar el rasgo capital del lenguaje, su materialidad trascendente con respecto al sujeto. Esta noción de escritura, observa Habermas, con su juego infinito de huellas y diferencias despojadas de toda presencia original, se transforma en condición de posibilidad del lenguaje (oral o escrito). Pero ella misma, la escritura, se presenta inasible e indeterminable como un juego vertiginoso de remisiones que se juega a sí mismo, de espaldas a la voluntad de los sujetos hablantes y escribientes. Con esta idea - prosigue Habermas- Derrida no hace más que reeditar aquella historia del Ser que acaece con independencia del hombre y que se sustrae aquí o dona sentido allá, siempre en un acontecer que trasciende al sujeto. La escritura derrideana no sería sino una suerte de ontología negativa temporalizada (juego infinito del diferir como aplazamiento), que falla (al igual que Heidegger) en su intento de escapar a la filosofía del sujeto, quedando presa de un fundamentalismo del signo en tanto exterioridad material.

A juicio de Habermas, puesto que Derrida no se abre a la dimensión pragmática del lenguaje como praxis social comunicativa, no logra ir más allá de donde llegó Heidegger con su crítica a la metafísica. Sin embargo, reconoce al mismo tiempo en Derrida una mayor sensibilidad política y moral que la que había en su maestro. ${ }^{17}$

\section{La deconstrucción desdiferencia literatura y filosofia a favor de la retórica}

Habermas señala como la inevitable suerte de toda autocrítica radical de la razón, al menos toda aquella que no logre abrirse hacia la di-

17 Ibíd. p. 203. 
mensión comunicativa e intersubjetiva del lenguaje, el estar destinada a verse desbancada por sus propias pretensiones autorreferentes de demolición. Ello es lo que habría conducido intentos señeros como los de Nietzsche y Adorno, Heidegger y Derrida, a la aporía de ya no poder sustentar un discurso racional para criticar la razón, y a buscar en otras fuentes, como la estética o la iluminación mística, una modalidad crítica no racional que pueda pronunciarse en contra de la razón sin ver socavadas sus mismas bases. ${ }^{18}$ Según Habermas, es Derrida, heredero del intento heideggeriano por destruir la metafísica como filosofía sujetocéntrica, quien ofrece ahora una nueva vía de escape para la aporía de la autocrítica radical de la razón. La nueva vía es la retórica, y su ejercicio la deconstrucción como crítica literaria. Esto es, darse al ejercicio de leer los textos filosóficos como aquello que no pretenden ser; un cierto género literario.

Planteada así la crítica, ella ya no debe ser entendida como una empresa científica, sino más bien como una forma literaria. La crítica de la metafísica será más un arte que una ciencia. Sus cánones no serán los de la consistencia lógica y argumentativa, sino los de la retórica. Pero Habermas advierte que esto ha de poder llevarse a cabo si es que efectivamente los textos filosóficos no resultan ser sino un género literario más, al lado de la novelística, la poesía, la dramaturgia. De no ser así, leer filosofía como literatura se trataría de una maniobra tan caprichosa y arbitraria como tomar textos y medirlos según cualquier aspecto, intentando hacerlos rendir en ámbitos ajenos y extraños al suyo propio. Según Habermas, la disolución de la diferencia entre filosofia y literatura ha de sostenerse sobre una tesis fuerte que ponga la primacía de la retórica sobre la lógica como base para tratar cualquier texto como obra literaria. Si todo es retórica, entonces no hay propiamente tal textos filosóficos y científicos de un lado, y textos literarios o artísticos del otro. La autonomía o exclusividad de campo ya no puede ser reclamada ni para las artes ni para las ciencias. De esto se sigue, tal como lo recomienda Derrida, que pueden y han de leerse los textos filosóficos como ejemplares literarios, tanto como los textos literarios pueden y han de leerse como ejemplares filosóficos. Sin embargo, aquí y allá

${ }^{18}$ Ibid. pp. 225-226. lo que cuenta es la primacía de lo retórico por sobre lo lógico-argumentativo. Estamos en frente de algo así como una archiliteratura que tiene en su seno, tan sólo como un caso especial, al discurso filosófico y su función cognitiva, normativa y veritativa.

La distinción entre filosofía y literatura se apoya en distinciones más profundas como serio/no serio, ficción/verdad, literal/metafórico, forma/contenido. Estas distinciones jerárquicas, al ser desmontadas por la deconstrucción derrideana, dejan de ser operativas o se debilitan hasta tal punto que ya no cabe tratar al discurso filosófico como algo distinto al literario. Habermas se ocupa de la disputa librada entre Derrida y Searle con respecto al cometido de Austin, pues en ella se debate precisamente la posibilidad o no de sostener las distinciones habituales entre lenguaje serio o simulado, ordinario o ficticio, normal o desviado.

Mientras J. Culler ${ }^{19}$ sostiene que Derrida logra efectivamente desmontar estas distinciones mostrándolas como insostenibles, Habermas argumenta que la distinción sigue siendo pertinente pues separa los actos de habla cuya fuerza ilocucionaria se lleva a cabo, de aquellos en que dicha fuerza se ha perdido. En unos la fuerza ilocucionaria permite efectivamente la coordinación de la acción de los participantes, mientras que en los otros no hay consecuencias directas para la acción. El habla ordinaria o normal, aquella mediante la cual nos comunicamos y coordinamos nuestras acciones en la vida diaria (en una promesa, una petición, etc.), está sujeta a exigencias y restricciones que quedan suspendidas cuando se trata de un simulacro, o de una escenificación. Cierto es que se puede citar textualmente una promesa en medio de una actuación teatral, pero de ahí no se sigue que ambas promesas (la original dicha en serio, y la actuada) estén sujetas a las mismas condiciones pragmáticas. En el primer caso lo que ha de quedar satisfecho es el acto de habla de la promesa, el cual se satisface cuando finalmente lo prometido se cumple, mientras que en la actuación lo que ha de satisfacerse es la simulación misma, que mientras más cercana al caso real mejor cumplida queda. Pero en ningún caso podríamos exigir a la promesa teatralizada el que quede cumplida en tanto acto de habla.

\footnotetext{
${ }^{19}$ Culler, J., Sobre la deconstrucción. Madrid: Cátedra, 1984.
} 
Ahora bien ¿cuáles son las restricciones que enmarcan el habla ordinaria y los actos de habla que allí se dan, de tal modo que les permiten a éstos coordinar la acción y producir consecuencias relevantes para la acción? Habermas dirá que se trata de suposiciones idealizadoras que no tenemos más remedio que hacer cuando actuamos comunicativamente, $\mathrm{y}$ que tienen que ver con la asunción de condiciones normales para el mundo que envuelve a los hablantes (algo así como la suposición de un ceteris paribus conversacional).$^{20}$ Esta suposición es de carácter prerreflexivo y holista, porque asume que una comprensión básica o mínima es compartida entre hablante y oyente, un fondo común que viene a ser nada menos que el mundo de la vida de una comunidad lingüística. El punto es que el hecho de que el significado de un enunciado no se agote en sus condiciones internas de referencialidad, y que dependa de las reglas pragmáticas que gobiernan su uso, no trae como consecuencia un relativismo semántico tal como lo quiere Derrida. Los hablantes cuentan con condiciones normales de actuación lingüística porque son capaces de configurar un mundo compartido de reglas, juegos, y regularidades que les permiten fijar significados. Estas presuposiciones constituyen el fondo necesario que los hablantes necesitan para llevar a cabo su acción comunicativa, y aun cuando cabe verlas como idealizaciones, ellas lo son en tanto funcionales al lenguaje ordinario y no en tanto teorizaciones logocéntricas venidas de una metafísica centrada en el sujeto.

Habermas denuncia aquí el descuido de Derrida con respecto al lenguaje ordinario. Y denuncia también la extracción de afirmaciones paradójicas como las de "todo entender es un malentender". En efecto, del hecho de que el significado de un enunciado dependa del contexto en el que se usa, no se sigue que por cambiar continuamente un enunciado su contexto, haya de errar interminablemente en falsas interpretaciones. Una vez más esto queda de manifiesto al atender a las prácticas cotidianas de entendimiento en actos comunicativos. Cuando dos personas se comunican, lo que hacen básicamente es coordinar su acción, y hay acuerdo o entendimiento mutuo cuando la coordinación efectivamente se produce. Mientras más urgen-

${ }^{20}$ Habermas, J., El discurso filosófico de la Modernidad. Madrid: Taurus, 1989, pp. 238-240. te o relevante para su acción resulte el ponerse de acuerdo, tanto más acuciosa se torna la interpretación y más en cuenta se tiene la posibilidad de tal acuerdo. Obviamente esto puede ir decreciendo gradualmente, pero nunca puede perderse del horizonte la posibilidad de que en último término los participantes lleguen a acuerdo, a un compartir intersubjetivamente los significados. El lenguaje cotidiano está continuamente sometido a esta exigencia de una idealización que supone la posibilidad de compartir significados intersubjetivamente, y esto porque en el lenguaje cotidiano coordinamos acciones relevantes para nuestro vivir.

En la literatura en cambio la fuerza ilocucionaria está depotenciada, sólo opera miméticamente y no tiene influjo directo en la acción de los participantes. La promesa que aparece en la obra de teatro no es recogida por nadie como promesa efectiva, nadie va a exigir después que el actor cumpla lo que dijo. Esta obligación está eximida en el lenguaje literario y se suspenden por tanto las consideraciones pragmáticas que en el lenguaje corriente de común se exigen. Esto no quiere decir que en el lenguaje corriente no se han de dar también actos de habla cuya fuerza ilocucionaria esté debilitada ex profeso, como ocurre en el chiste, la ironía, o la anécdota que se narra en un relato que se entiende condimentado con fantasía. Sin embargo, ello no invalida la demarcación entre lenguaje literario y lenguaje ordinario. Las presuposiciones idealizadoras que ponemos en juego cuando nos comunicamos en el habla corriente, tienen que ver con máximas conversacionales (Grice) tales como: que el hablante está tratando de ser lo más claro e informativo posible, que no está omitiendo información pertinente, que está siendo sincero en lo que comunica, y que está evitando la oscuridad, ambigüedad y complicación en su expresión. Según Habermas, estas exigencias idealizadoras que hacen posible como trasfondo el acto comunicativo normal, son las que quedan suspendidas en el lenguaje literario posibilitándolo como tal. En dicho lenguaje no sólo perdonamos la ampulosidad y complicación de la forma expresiva, la elipsis y la incompletitud, la ambigüedad y equivocidad de lo que se está diciendo, sino que además la buscamos y premiamos de cierta manera cuando en y por ella hemos conseguido un goce estético. Claro está que la pura liberación de estas exigencias y restricciones funcionales y pragmáticas no alcan- 
za para dar cuenta de una obra literaria, pero sí constituye su condición de posibilidad.

No obstante esta distinción, Derrida insiste en desdiferenciar el lenguaje literario del lenguaje normal o corriente mediante una doble negación de especificidad: no hay especificidad para el lenguaje poético-literario como tampoco la hay para un lenguaje no-poético-literario. Todo es retórica. De esta forma, señala Habermas, Derrida pasa por alto el hecho de que el lenguaje cotidiano se encamina hacia la solución de problemas, mientras que el lenguaje literario lo hace hacia la apertura de mundos nuevos posibles. Las prácticas comunicativas que el lenguaje cotidiano vehicula son aquellas en virtud de las cuales se despliegan los procesos de socialización, educación, formación de identidades y personalidades, transmisión de valores culturales y tradiciones. Allí se juegan asuntos del mundo de la vida, cuestiones que requieren la acción coordinada de una comunidad toda. Los problemas del mundo de la vida se abordan mediante lenguajes que pretenden validez normativa y veritativa, y así es como toman cuerpo los distintos discursos que se especializan en abordar estos problemas. Los del saber en la ciencia, los de la justicia en el derecho, los de la práctica en la moral. Todos ellos dedicados a la solución de problemas y no a la apertura de mundos posibles.

La asimilación de la literatura a la filosofia y de la filosofía a la literatura que propone Derrida en su disolución de géneros, constituye a juicio de Habermas una forzada maniobra de homogeneización que confunde la mera presencia de una dimensión lingüística con su rol efectivo en el discurso y el habla. El habla cotidiana, el discurso filosófico, el científico, el político, el jurídico, el ético y moral, desde el momento en que son lenguaje llevan inevitablemente una dimensión retórica que les es inmanente en tanto lenguaje. Pero la diferencia con el lenguaje poético-literario es que en ellos esta dimensión pasa a segundo plano y se la deja como fondo. No son lenguajes encaminados a la apertura de mundos sino a la solución de problemas de un mundo que se da ya por compartido. Por lo tanto en ellos la dimensión retórica, aunque omnipresente, queda relegada como una función subsidiaria a las funciones veritativas y cognitivas, una función que puede o no ponerse al servicio de una más importante cual puede ser la coordinación de la acción en cierta dirección y no en otra. En cambio, cuando se trata del len- guaje poético-literario, la dimensión retórica pasa a ocupar el primer plano y se torna por sí misma el fin último de dicho lenguaje. Y cabría decir que, a su vez, no procede tampoco aquí pensar que la dimensión lógica y veritativa del lenguaje está extirpada, sino que más bien está relegada ahora a un plano secundario, pues se trata esta vez no de solucionar problemas dentro de un mundo ya dado sino de iluminar nuevos mundos posibles a través de juegos lingüísticos libres de requerimientos pragmáticos.

El ironismo contingente de Rorty: observaciones sobre Derrida y Habermas

A juicio de Rorty, la crítica que establece Habermas con respecto al último Heidegger y a Derrida, simplemente es una versión diferente de aquella crítica que en su tiempo levantara Carnap frente al Heidegger de Sery Tiempo. En ambas críticas lo que se sostiene es la idea de que la filosofia ha de ser a fin de cuentas una cuestión de argumentación racional. Rorty no acepta la distinción que Habermas establece entre lenguajes 'solucionadores de problemas' y lenguajes 'abridores de mundo', al menos como una que sirva para deslindar claramente entre filosofía por una parte y literatura por otra. Observa que lo que aúna a filósofos de un lado y a literatos de otro es simplemente una cuestión institucional. Según Rorty, más bien cabe admitir de hecho "...que los escritores habitualmente identificados como 'filósofos' incluyen tanto solucionadores de problemas y argumentadores como Aristóteles y Russell como revelamundos oraculares como Platón y Hegel -personas buenas tanto en presentar explicaciones públicas como en saltar a la oscuridad". ${ }^{21}$

Lo excepcional de obras como la de Hegel, Heidegger y Derrida, que aparecen como revelaciones poéticas de mundos, se paga inevitablemente con el precio de abandonar en cierto punto el terreno de la argumentación y rigor conceptual. Pero ello no deprecia a estas obras en ningún sentido intelectual. Es o sería una necesidad casi intrínseca del lenguaje el liberarse de estos requerimientos, cuando quiere alumbrar el misterio y avanzar hacia la apertura de otros mundos posibles. De esta forma no cabe

${ }^{21}$ Rorty, R., Ensayos sobre Heidegger y otros pensadores contemporáneos. Barcelona: Paidós, 1993, p. 175. 
entonces una divisoria entre filosofia y literatura, ni aun una entre filosofía y no-filosofía. Lo que sí puede distinguirse es más bien una divisoria entre aquellos temas en los que sabemos cómo argumentar y aquellos en que no.

Sin embargo, Rorty concuerda con Habermas en el hecho de que no pueden tomarse como argumentaciones construcciones lingüísticas que no lo son. Ambos rechazan la idea de que se pueda adoptar una posición no proposicional y reclamar simultáneamente un estatus argumental para dicha posición. Así, lo que cabe distinguir en Derrida sería la magnífica obra de un subvertidor de categorías lingüísticas, un revelamundos que opera y se ejercita en el "fluidificar antiguos vocabularios"22 Pero no cabría reconocer en términos como deconstrucción o différance tesis argumentativas propiamente tales. Las operaciones retóricas en las que se mueve Derrida le permiten precisamente desplazarse aquí y allá con soltura deconstruyendo textos, mas tales operaciones no desacreditan a la deconstrucción como genuina filosofía.

A diferencia de Habermas, Rorty no concibe el quehacer filosófico como uno que ha de inscribirse en el exclusivo ejercicio de la argumentación. Si es cierto que las operaciones deconstructivas derrideanas no pueden ser presentadas como argumentaciones, ello no significa luego que haya que desconocer en ellas un ejercicio filosófico que se despliega como revelador de mundos y órdenes posibles. Y este 'revelador' de mundos, advierte Rorty (un declarado nominalista), no ha de entenderse como un 'descubridor' de realidades subyacentes sino más bien como un 'inventor' o 'creador' de tales mundos.

Para este autor, cuyo ascendente se sitúa en la corriente postanalítica norteamericana de la filosofía del lenguaje, el tipo de filosofía que Habermas se empeña en restaurar resulta hoy por hoy un verdadero obstáculo para el mantenimiento y preservación de las sociedades democráticas. Conceptos ilustrados como los de verdad, racionalidad, y obligación moral, son conceptos que han de abandonarse en pro de una concepción no racionalista ni universalista de la sociedad contemporánea.

La figura del filósofo y el rol de la filosofía en general son profundamente depotenciados

${ }^{22}$ Ibíd, p. 179 por este autor, quien señala que sería mejor no entender a la filosofía como cumpliendo una función social importante, o como siendo fundamental para pensar la política, la ciencia, o la moral. El filósofo que ha de necesitarse ahora no es el metafísico ni el neoilustrado, sino el ironista liberal. Éste es un intelectual que reconoce sin más la radical contingencia de todos sus valores y creencias más fundamentales, que es capaz de aceptar la historicidad y relatividad de todo pensamiento, y que lúcidamente sabe que nada tiene ni una naturaleza intrínseca, ni una esencia, ni un principio ordenador o propósito final. También el ironista liberal, según el propio Rorty, es un exponente de aquello que autores como Gianni Vattimo y Pier Aldo Rovatti han llamado il pensiero débole, es decir, un filósofo que no intenta ya una crítica radical de la cultura contemporánea en la que le toca vivir, ni intenta reformularla o refundarla desde ningún sitio privilegiado. ${ }^{23}$

Este antiuniversalismo y antirracionalismo profesados por Rorty lo ubican en franca oposición al proyecto habermasiano de restaurar el valor de la razón, y lo acerca en cambio a aquellas figuras de las que Habermas precisamente desconfia: Nietzsche, Heidegger, y Derrida. Frente al propósito habermasiano de poner al día tanto al universalismo como a la razón, Rorty propondrá más bien “...disolver a ambos y sustituirlos por una cosa distinta". ${ }^{24}$ Frente a la preocupación por la validez universal de lo pensado, propondrá dejar de preguntarse por dicho asunto y entregarse a la posibilidad de vivir y convivir en la pluralidad. Según Rorty, no necesitamos de ningún proyecto restaurador de la razón, ni siquiera de aquél que pretende sustituir en la forma de una razón comunicativa (Habermas) aquella antigua y metafísica razón centrada en el sujeto.

Pero aun cuando Rorty se sitúe junto a Derrida en su oposición a cualquier atisbo de razón universal, no concuerda con aquél en todos los respectos, o más bien, parece no acompañar del todo la actitud filosófica que Derrida sugiere para la deconstrucción. Entre otros puntos críticos señalados por Rorty podemos destacar aquí los siguientes. ${ }^{25}$

\footnotetext{
${ }^{23}$ Ibíd. p. 22.

${ }^{24}$ Rorty, R., Contingencia, Ironía y Solidaridad. Barcelona: Paidós, 1996, p. 63.

${ }^{25}$ Rorty, R., Ensayos sobre Heidegger y otros pensadores contemporáneos. Barcelona: Paidós, 1993, p. 128.
} 
- La tesis, que comparten Heidegger y Derrida, de que la tradición ontoteológica ha dominado de punta a cabo la ciencia, la literatura y la política, constituye más bien un intento engañoso por aumentar la importancia de una especialidad académica.

- La importancia de Derrida no consiste en mostrarnos la formas de entender lo filosófico como literario o lo literario como filosófico. Ya sabemos hacer bastante bien ambas cosas. Más bien consiste en desarrollar una determinada especialidad académica (o tradición literaria, que viene a ser lo mismo), a saber, la relectura de la filosofía occidental iniciada por Nietzsche y proseguida por Heidegger.

- El gran problema esotérico común a Heidegger y Derrida de cómo 'superar' la tradición ontoteológica, es artificial y tiene que ser sustituido por un conjunto de preguntas y consideraciones pragmáticas más pequeñas (ver qué fragmentos de dicha tradición podrían sernos útiles para alguna necesidad actual).

Rorty observa que Derrida gusta de mostrar en cada pretensión filosófica totalizante, cada intento de clausura de la marea interminable de interpretaciones filosóficas, la imposibilidad de este cierre. Haciéndonos ver los márgenes, lo suplementario, lo que se ha obviado o declarado ininteligible, nos revela justamente aquello que posibilita o es precondición de lo inteligible. Pero releer a los filósofos, revisar la filosofía y su historia, advierte Rorty, finalmente es casi volver a hacer lo que los filósofos tradicionalmente hacen, pues con ello se cae en nuevas generalizaciones o promulgaciones de imposibilidades.

Derrida se acerca peligrosamente a este filosofar desde el momento en que es capaz de ofrecer un léxico nuevo de nivel metalingüístico. Palabras como différance, huella, o archiescritura, traídas a cuenta de apoyo argumentativo para tesis como 'la escritura es anterior al habla' o 'los textos se deconstruyen a sí mismos', son conceptos cuya naturaleza conceptual no puede ser borrada por simple decreto derrideano, por más que el autor se empeñe en advertir que aquellas marcas no son ni conceptos ni argumentaciones.

Para Rorty, la labor de Derrida es precisamente sugerir nuevas formas de hablar y pensar los asuntos que nos preocupan, no realizar argumentaciones. Por ello denuncia Rorty la in- clinación derrideana a enfatizar a ratos lo 'riguroso' de su labor. Cada vez que Derrida se esfuerza por argumentar en favor de sus puntos de vista y sugerencias, traiciona el propio proyecto que quiere llevar a cabo. ${ }^{26}$ Este proyecto, coincide en este punto Rorty con Habermas, es llevar a buen término lo que Heidegger emprendiera fallidamente en su crítica a la metafísica. Pero lo que Derrida ofrece como novedad -el situarse en consideraciones retóricas y jugar con las palabras como si fuesen sonidos, despreciando el carácter lógico inferencial que pueda unirlas-resulta ser a juicio de Rorty un fenómeno que pertenece a la historia misma de la filosofia $\mathrm{y}$ de las disciplinas en general.

Rorty incorpora aquí el esquema histórico que Kuhn desarrolló para las ciencias y lo aplica en la observación de la historia de la filosofía. En términos muy gruesos el esquema distingue dos momentos característicos en el desarrollo de una disciplina; una fase acumulativa en la que las ideas se acomodan a un conjunto de reglas y estructuras consensuadas por la comunidad disciplinar (ciencia normal la llama Kuhn), y una fase de revolución en la que un estado de crisis de los consensos comunitarios suscita la competencia de nuevas visiones o modelos que pugnan por tomar el dominio de la disciplina y reordenarla bajo un nuevo paradigma (revoluciones científicas). ${ }^{27}$ En estas fases de crisis y revoluciones, que se intercalan cada tanto con fases de normalidad, lo que se produce es la generación de nuevos vocabularios, nuevos conceptos que tratan de atrapar un nuevo estado de cosas o un conjunto de problemas hasta el momento no vislumbrados. No hay consenso, justamente el orden entra en crisis por esta falta de consenso que produce la acumulación de anomalías (problemas novedosos que no tienen solución desde el paradigma vigente hasta ese entonces), y no hay por tanto una base común sobre la cual esgrimir argumentos ni menos aún poder medirlos bajo algún canon

\footnotetext{
${ }^{26}$ Rorty pareciera exigir ser más derrideano que el propio Derrida, tal y como en su momento Derrida parecía exigir a Foucault más locura que la que el propio filósofo ofrecía en su Historia de la Locura. Para este ejercicio de lectura que desvela cómo el texto foucaultiano se traiciona a sí mismo en su pretensión crítica, ver "Cogito e Historia de la Locura", en Derrida, J., La escritura y la Diferencia, Barcelona: Anthropos, 1989.

${ }^{27}$ Kuhn, Th., La estructura de las revoluciones cientificas. México: FCE, 1971.
} 
normativo. ¿Qué hay entonces?, hay subversión, confusión, caos, y multiplicidad de propuestas afanosas de tomar el trono del paradigma que ha sido depuesto. Estas fases de revolución Rorty las asimila a fases 'literarias' o 'poéticas', justamente porque se orientan no a la solución de problemas ordinarios (solución de acertijos los llama Kuhn) sino a la apertura de mundos.

Pues bien, lo que Derrida supone que está haciendo como gesto singularísimo en la historia de la filosofía, no es más que lo que ya han hecho en su momento y en sus respectivas disciplinas aquellos personajes (pensadores, científicos) revolucionarios y originales; tomar las palabras heredadas y torcerlas hasta dotarlas de un nuevo sentido, crear neologismos y dotarlos de significaciones suigéneris. Todos quienes en su momento han sido revolucionarios en este sentido, han sido blanco de los ataques conservadores, que no ven en dichos gestos más que una trasgresión de las reglas, un juego irresponsable de imaginaciones o lucubraciones sin base, una utilización meramente retórica del discurso y una falta de argumentación lógica. Rorty observa que la ciencia física y la metafísica que han marcado verdaderos cambios y revoluciones han sido siempre 'literarias', en el sentido de que han afrontado el arduo problema de introducir una nueva jerga y abandonar las categorías y juegos lingüísticos vigentes hasta ese entonces.

Literatura y filosofia, retórica y argumentación lógica, lenguaje solucionador de problemas y lenguaje abridor de mundos, toda vez que se los piensa como categorías distintas, no pasan de ser sino idealizaciones o tipos ideales que tienen meramente un carácter heurístico, pero que no reflejan la historia efectiva de lo que de hecho ocurre en el desarrollo ni de la ciencia ni de la filosofía. Así, lo que Derrida contrapone y luego con gesto de gran provocación pretende estar subvirtiendo en su deconstrucción, no son sino tipos ideales construidos ad hoc para tal propósito. ${ }^{28}$ Lo cierto es que las cosas no son tan así como Derrida pretende que sean, no hay tal cosa como un pensamiento totalizador metafísico omniabarcante que venga desde Platón en adelante sometiendo y subordinando todos los ámbitos de la cultura occidental. Aquel edi- ficio de la ontoteología, tan imponente y subyugador, tan perfecto y eficaz en su gobernabilidad, tan dominante en su superacontecer determinador de todo lo intramundano, no es tanto un hecho indesmentible de la historia de la filosofía cuanto una construcción idealizada -heideggeriana y luego derrideana- para propósitos de hacer luego más visible y más sonora su destrucción o deconstrucción.

En este punto la observación crítica de Rorty se acerca en buena medida a lo señalado por Habermas con respecto a autores como Adorno, Heidegger y Derrida. Habermas también advierte algo de artificialidad en la presentación del problema capital que se supone estos autores están arduamente enfrentando. A su juicio, estos autores se comportan como si vivieran, cual los inmediatos poshegelianos, bajo la sombra aplastante del último sistema metafísico total y absoluto. Se esmeran y no escatiman esfuerzos en dar batalla a aquellos conceptos 'fuertes' de teoría, verdad y sistema que, desde hace ya por lo menos ciento cincuenta años pertenecen al pasado. Creen que aún está pendiente la tarea de despertar a la filosofía de lo que Derrida llama 'el sueño de su corazón', la gran ingenuidad de pretender dar la última palabra, la última interpretación, el remate conceptual que cierre en forma total y sin residuos la intelección del mundo y del hombre. ${ }^{29}$ Estos tremendos esfuerzos, estas arremetidas de gran espectacularidad sin embargo, no pasarían de ser a estas alturas de la conciencia filosófica -en el mejor de los casos- algo así como zarandear a un gigante ya muerto y en descomposición.

En efecto, y esto es lo que conduciría los proyectos de estos autores al callejón sin salida de la autocrítica radical de la razón, si la razón filosófica dependiera en su totalidad de la vigencia de ideas y nociones tan fuertes como la de Verdad, o de aquellas metas clásicas de intelección absoluta que la metafísica persiguió desde Parménides hasta Hegel, "entonces una adecuada crítica de la razón tendría (...) que calar tan hondo, que apenas podría escapar a la paradoja de la autorreferencialidad". ${ }^{30}$

\footnotetext{
${ }^{28}$ Rorty, R., Ensayos sobre Heidegger y otros pensadores contemporáneos. Barcelona: Paidós, 1993, p. 144.
}

${ }^{29}$ Habermas, J., El discurso filosófico de la Modernidad. Madrid: Taurus, 1989, p. 253.

${ }^{30}$ Ibíd. p. 253. 


\section{Algunas consideraciones finales}

En el escenario del pensamiento contemporáneo puede sostenerse razonablemente una separación gruesa entre una posición neoilustrada que defiende la vigencia de la racionalidad, la universalidad, la restauración del proyecto crítico de la modernidad, la concepción de la filosofía como 'antorcha de la historia' (la imagen es de Horkheimer), y una posición - en este sentido posmoderna- que rechaza (o pone bajo una profunda sospecha) la razón universal, los metarrelatos homogeneizantes propios de la modernidad, y la presunta posición privilegiada de la filosofía como garante del desarrollo y porvenir de la sociedad contemporánea. En la primera posición hemos de situar a Habermas y su teoría de la acción comunicativa, su ética discursiva, y su tesis de la modernidad como proyecto inacabado (léase 'por llevar a cabo'). ${ }^{31}$ En la segunda hemos de ubicar a Derrida y su filiación nietzscheana de crítica radical al conjunto todo de la filosofía occidental, de la cual la modernidad no sería sino el vástago más reciente.

En la primera posición, aquella que defiende la viabilidad del proyecto ilustrado, lo que se juega es la posibilidad de dar fuerzas renovadas a una ética con alcance universal. Mientras que en la posición posmoderna tal pretensión de universalidad es abandonada. Teóricos como Derrida (junto a Foucault y Lyotard) renuncian a dichas pretensiones de universalidad por cuanto tras ellas se sospecha el contrabando de ideas totalitarias, coercitivas y disciplinarias. Esta desconfianza frente al planteo de una ética universal, se extiende en general a la mayoría de las nociones clásicas que acompañaron al proyecto moderno. Se mira con recelo conceptos como razón, verdad, unidad, igualdad, objetividad, identidad, progreso, y emancipación, entre otros. Antes bien desde estos autores posmodernos el mundo aparece como contingente, inexplicado, diverso, múltiple, e indeterminado. ${ }^{32} \mathrm{Se}$ teme, y cabría señalar que con justificada razón, que en nombre de una normativa universal

${ }^{31}$ Habermas, J., Modernidad: Un Proyecto Incompleto. En N. Casullo (comp.), El debate Modernidad Posmodernidad. Buenos Aires: Puntosur, 1989, pp.131-154.

32 Eagleton, T., Las ilusiones del posmodernismo. Buenos Aires: Paidós, 1997. Citado por Barrientos, J. P., El dilema de la ética: la ilusión neoilustrada o la renuncia posmoderna. En "Anuario de Postgrado", Facultad de Filosofia y Humanidades, Universidad de Chile, 2003, $N^{\circ} 5$, pp. 123-144. se borre no sin violencia la gran diversidad de formas de existencia y la pluralidad de ethos culturales particulares. Lyotard ${ }^{33}$ traza en este punto una viva crítica a la propuesta habermasiana de una ética discursiva (argumentativa) universal, basada en el consenso generalizado. Acusa a esta pretensión de no ser más que un nuevo 'metarrelato' emancipatorio, y por ello, iluso y a la vez peligroso. Versus la universalidad se levanta aquí el contextualismo, o sea, el apego por derecho a lo local y a sus propias normas idiosincrásicas.

Al enmarcar el tema de la relación filosofia/ literatura en esta discusión más amplia de la ética contemporánea, podemos ver aparecer de mejor forma el profundo contraste entre las posiciones adoptadas por Habermas y Derrida. No es dificil vislumbrar desde este contexto que lo que está en juego en esta discusión es la posibilidad o no de sustentar racionalmente un discurso capaz de levantar una normativa ética universal para los seres humanos. Es decir, lo que Habermas no está dispuesto a aceptar es la cancelación de un proyecto ético basado en la racionalidad. Desde su punto de vista, disolver los límites entre los discursos filosóficos y literarios traería como resultado la nefasta retorización de la ética, su licuefacción en tropos y ficciones a los que no cabría ya atender como normativos, en el sentido de que siendo no más que un conjunto de textos a los que no cabría medir ya sino en cuanto a su estilo y fuerza retórica, se la despojaría de todo poder ilocucionario perdiendo así su efecto vinculante en la praxis social. Efecto que es precisamente el que se busca en los enunciados éticos.

Habermas acierta aquí a mi modo de ver en su observación, puesto que todavía sin siquiera plantearnos el asunto de si la ética ha de ser universal o estrictamente contextual, es un hecho de suyo connatural a lo ético el estar orientado a la coordinación de la acción entre sujetos distintos, diferentes, que precisamente por no ser idénticos ni formar parte de una única y misma conciencia, deben procurar establecer formas mínimas de comunicación y de reglas que los guíen en su actuar. Sobre todo allí donde el fondo transparente que teje la suposición de un mundo compartido por los hablantes (idealización inevitable para poder comunicarse), se rom-

\footnotetext{
${ }^{33}$ Lyotard, J.-F., La condición posmoderna. Madrid: Cátedra, 1986.
} 
pe de súbito con la experiencia de la ofensa, la desavenencia y la discordia. En estos casos, lo que se busca muy naturalmente es un acuerdo o una regla reparativa (la analogía aquí con la reparación de quiebres conversacionales de la pragmática es clara y generosa a la vez) que permita restaurar la integridad del ofendido a través de alguna acción que valga como tal para ambas partes. Por tanto, lo dicho o escrito en y para este trance de la experiencia moral (que siempre es originalmente experiencia de la ofensa, del quiebre) tiene como intención o propósito consciente el conminar de algún modo a que los implicados se adhieran a lo dicho y lo asuman como un acuerdo que los comprometa de un modo más o menos fuerte a actuar en consecuencia. Es decir, lo dicho o escrito a propósito de este tipo de experiencias intersubjetivas ha de plantearse necesariamente como algo a observar para el actuar, y no como algo a observar en sí mismo en sus determinaciones de forma o estilo de cómo se haya dicho o escrito.

Creo además que en estas consideraciones, arrimarse con cautela a una mirada pragmatista como la de Rorty puede iluminar algo más el debate. Pues ¿qué es un determinado acto de habla sino lo que en buenas cuentas resulta ser una vez que ha tenido lugar? Sabemos que una disculpa no es tal por la mera intención de quien la ejecuta, que si el que la ha de recibir no la entiende o interpreta como tal la disculpa en cuestión no ocurre. Así mismo qué sea o no una explicación viene a quedar determinado por quien la recibe, por quien estipula para sí cuándo y de qué modo se ha de dar por satisfecho y aclarado respecto de su duda o interrogación. Como hemos señalado más arriba, lo que de suyo piden los enunciados éticos es que se los atienda en términos de consecuencias para la acción de los implicados. Pero cómo ha de quedar satisfecha esta demanda lo determinan los usuarios o destinatarios.

Visto así, en verdad lo que se necesita no es saber si es que los enunciados de la ética son o no literatura, y ni siquiera saber si es que pueden o no ser leídos-escuchados como literatura. Todo esto puede ser efectivamente así, pero lo que hará éticos a unos enunciados y no a otros será finalmente el uso que de ellos se haga. Y el cómo se usen las palabras y lo dicho depende de las necesidades y requerimientos del caso. Así, si hemos naufragado de pronto en la experiencia de quiebre que es la ofensa moral, el pro- blema inmediato que se nos impone es la solución y reparación de este quiebre, con miras además a que tal experiencia no se repita en adelante. Siendo esta la necesidad que arroja la experiencia moral, el uso prescriptivo que adopta lo dicho y comunicado en ese trance es lo que determina su carácter ético, y no la naturaleza interna o semántica en un sentido estrecho de los enunciados. Éticos son los enunciados que una comunidad determinada considera útiles para dar solución a este tipo de problemas morales, y esta consideración de utilidad opera en estricto pragmáticamente, puesto que las éticas se conservan o se desechan según nos sirven o no a nuestros propósitos.

Que estos propósitos puedan torcerse unilateralmente hacia la extracción de beneficios egoístas y exclusivos, es algo que no invalida el criterio pragmático sino que más bien lo modula en términos asimétricos. Si el discurso ético de la religión cristiana -como en su momento lo presentó Marx-es en alguna medida parte de la ideología con que las clases dominantes aseguran la perpetuidad de su condición, de forma tal que a los oprimidos puede hacérseles claro en algún momento que lo que se suponía resguardaba la integridad de todos por igual estaba tendenciosamente cargado hacia el beneficio de tan sólo un determinado sector de la comunidad, no cabría sin embargo pensar que tal ética no es funcional o que no es útil para resolver los problemas a los que se dirige. Simplemente cabría observar que la aceptación del discurso religioso por unos y por otros, por el sólo hecho de que en virtud de esa aceptación lo hacen funcionar y lo usan efectivamente como regla de comportamiento, constituye de hecho un discurso ético, el cual sólo por ser reconocido primero en su capacidad vinculante puede luego ser criticado como desigual, engañoso e ideológico.

Resulta claro desde un comienzo que la defensa habermasiana de la especificidad de los discursos filosófico y literario no está motivada por una mera discusión de géneros. Hay algo que quema sensiblemente la conciencia ilustrada de Habermas cuando Derrida pretende presentar a la filosofía tan sólo como un particular género literario. Para Habermas es de suyo evidente que-sin ir más lejos-los textos que salen de su pluma no tienen como pretensión la fascinación estilística del juego retórico, sino la muy seria y solemne intención de argumentar en favor de una propuesta ética y de una concepción 
de lo social que puede eventualmente reconducir nuestras vidas. No está dispuesto por lo tanto a que la validez de lo que él escribe, se zanje por un asunto de crítica literaria y estilística, aun cuando puede muy bien estar consciente de que su prosa puede ser objeto de comentarios estilísticos.

Cierto es -y qué duda cabe- que todo lo que aparece escrito aparece escrito de algún modo y no de otro, y que siendo siempre posible expresar en más de una forma la idea o argumento que se quiere comunicar, un asunto de estilo estará siempre por fuerza implicado en toda comunicación, en todo acto de habla, en toda escritura. Habermas no niega el hecho evidente de que los escritos filosóficos, ya por el sólo hecho de ser escritos (y no por ser filosóficos), son terreno fértil para consideraciones y análisis retóricos y estilísticos. En último término, la auscultación del estilo y forma discursiva de cualquier cosa dicha o escrita, es algo que podemos perseguir legítimamente hasta en carteles publicitarios, en constituciones de estados, en boletas y facturas, etc. Lo que Habermas no está dispuesto a tolerar es que toda la lectura del texto filosófico se agote en este ejercicio de crítica literaria, que todo lo que ha de tenerse en consideración sea la revisión de los tropos y figuras que se trafican en el discurso filosófico, como si eso fuera en última instancia lo que nos revela la inconsistencia o no de lo dicho, su validez y su estatus cognitivo-normativo.

Del hecho de que efectivamente todo lo dicho y escrito sea citable, repetible, susceptible de ser sacado de su contexto original e injertado en otro extraño, no se sigue luego el hecho de que la fuerza ilocucionaria de lo dicho o escrito pierda por ello su poder vinculante y coordinador de acciones. Digamos, ¿qué hacemos luego de dar como veredicto el que nos parezca más logrado el estilo literario de Mill y Bentham, que el de Marx y Engels?, ¿se sigue de ahí que hemos de adoptar el modelo ético y social propuesto por aquellos en vez del propuesto por los otros?, ¿no atendemos naturalmente a otro tipo de consideraciones, más allá de la estética o estilística, cuando en el asentir o no a lo que se nos está diciendo advertimos que nos va la vida toda y la de nuestros semejantes? Si es claro el hecho de que tanto los unos como los otros se valen de recursos retóricos en sus argumentaciones, porque en verdad ya sabemos que no hay otro modo de valerse a la hora de levantar un discurso, si es claro también que lo escrito (dicho) por unos y por otros por el simple hecho de ser escrito es ya literatura, escritura, no es menos claro a la vez el hecho de que en ningún caso nos contentamos con este tipo de consideraciones a la hora de dar la razón a uno o a otro, ni nos damos por satisfechos con un veredicto puramente literario a la hora de decidir actuar en consonancia o no con respecto a lo que unos y otros nos están proponiendo.

Precisamente porque los niveles discursivos cognitivo y estético, moral y estilístico, de contenido y de forma, lógico y retórico, son capaces de moverse con total independencia, es que pueden aquí o allá y en distintas ocasiones, cobrar alianzas de distinto tipo y fuerza, suscitando en distintos auditorios reacciones diferentes. Veamos esto con algunos ejemplos. En el acto de habla que podríamos llamar de seducción, quien se apresta a ser seducido dispone como su escucha la atención predominante a los aspectos retóricos de lo que se le va a decir, muchas veces haciendo caso omiso de lo flagrante o no que pueda resultar la falsedad o inverosimilitud de lo dicho. El auditorio no está interesado en el valor cognitivo-veritativo de las palabras que escucha al oído, sino en la armonía o belleza con que se lo está adulando y jurando amor eterno. La seducción efectivamente ocurre y el acto de habla se cumple, cuando el auditorio actúa luego en consonancia con lo que se supone cabe esperar cuando una seducción se ha llevado a cabo. En este caso el auditorio permanece fiel a su ánimo. No importa cuán verdad sea lo que se le está diciendo, lo importante es la forma y el modo. Si alguien le revela con absoluta verdad y honestidad sus sentimientos, pero lo hace de la manera más torpe, burda y poco galante que cabe esperar, la seducción probablemente no ocurrirá.

Ahora bien, no siempre es el caso que el auditorio separe efectivamente estos niveles discursivos. A veces, y muy a su pesar después, el auditorio puede dejarse conducir por aquél nivel discursivo al que en primera instancia no iba a dar prioridad. Llamados a escuchar el discurso de algún candidato en medio de un proceso electoral, el auditorio puede asistir con el ánimo de atender fundamentalmente al contenido político y moral del discurso, haciendo abstracción de las orlas retóricas que se le ofrezcan. Pero muy bien puede pasar, y suele ser el caso recurrente, que la habilidad del orador 
maneje con tal astucia la retórica de su discurso, que el contenido último político y moral de su palabra sea enmascarado por la floritura estilística que le sirve de sostén. En tal caso, el auditorio puede ser persuadido en base a tales maniobras, incluso con el convencimiento de que su adhesión al candidato obedece a cuestiones de razón y fundamento. Pero más allá de estas situaciones que bien conocemos, lo que importa destacar es el hecho de que ni una ni otra son apoyo para sostener la tesis de que lo retórico, por subsumir y abarcar lo lógico y argumentativo, anula y disuelve a este último dejándolo sin poder vinculante ni fuerza ilocucionaria. Pues el hecho de que el auditorio sea persuadido por la retórica y no por la argumentación lógica del discurso, no hace sino mostrar que lo retórico está aquí instrumentalizado para conseguir finalmente el efecto de una fuerza ilocucionaria, conseguir finalmente que el acto de habla surta el efecto vinculante que se busca, coordinando la acción de forma tal que al momento de votar el auditorio se incline por el candidato en cuestión. Pues es esto y no la fascinación retórica per se lo que el discurso del candidato tiene como fin. Esto se ve más claro si es que ahora nos figuramos que el auditorio, luego de asistir al discurso y comentando con goce la belleza y refinamiento de las palabras del candidato orador, se dirige a las urnas y decide votar por el candidato opuesto. ¿Diríamos ahora que se ha cumplido lo que se pretendía en esta instancia comunicativa?, ¿queda satisfecha la intención del candidato y su discurso conmovedor si es que es copiosamente felicitado por su manejo poético, pero es abandonado en el voto?, ¿acaso no es claro que la dimensión retórica de su discurso estaba puesta al servicio de, instrumentalizada para, pero en ningún caso constituía un fin en sí mismo?

Esto contrasta tan visiblemente con lo que ocurre por ejemplo en una lectura poética, en la que el escritor lo que busca es el reconocimiento de la elaboración estilística por sí misma, que se hace difícil asimilar los distintos discursos a un mismo canon literario. En este caso, el escritor vería tan frustrado su cometido comunicativo como el candidato político, si es que el auditorio para el que lee su poesía le reconoce la rectitud moral de lo que ha dicho, la bondad de sus intenciones, lo informativo de sus versos, la abnegación y compromiso para con el oficio, pero desestima del todo que su poesía tenga al- gún valor estético o artístico. De allí a que el auditorio se vuelque a comprar ejemplares del libro de poesía porque su bello empaste promete como espléndido adorno en la estantería de la casa, habría sólo un paso.

La estrategia deconstruccionista de disolver las diferencias entre filosofia y literatura comporta para Habermas la neutralización del discurso ético y su debilitamiento. A pesar del tono subversivo y contestatario que Habermas observa en Derrida, la suma neta a su juicio de las estrategias deconstruccionistas a la hora de pronunciarse políticamente, es la de un nuevo conservadurismo. En una esquematización que Habermas ensaya respecto de las posiciones políticas del pensamiento contemporáneo,${ }^{34}$ distingue una extraña alianza antimodernista que aúna a conservadores viejos (premodernistas) y nuevos (posmodernistas), nostálgicos de la razón sustantiva los unos, escépticos irreverentes y desencantados los otros. Esta posición antimodernista de autores como Derrida y Foucault, es denunciada por Habermas como un escepticismo valórico que no puede sustentar ya una mínima normativa ética. Estos autores habrían confundido, junto con Heidegger, la universalidad que ha de acompañar a toda proposición argumentativa y normativa, con el pretendido carácter absoluto y definitivo que la filosofía tradicional reclamaba para sí en sus enunciados. Carácter que desde hace ya muchas generaciones la filosofía ha abandonado en pro de una posición donde no cabe la soberbia de proclamarse como teniendo un acceso privilegiado a la verdad o al conocimiento último de las cosas. Según Habermas, la conciencia falibilista de la ciencia (en alusión a Popper) ha permeado y corregido ya suficientemente la antigua ilusión filosófica de dar con la última palabra.

Sin embargo, a lo que no se puede renunciar es a la universalidad de las proposiciones filosóficas. Ellas no han de ser las definitivas, las que no tengan ya más cabida para interpretaciones distintas, pero sí han de ser aquellas que se ofrecen como válidas más allá de los contornos estrechos del aquí y ahora de nuestra experiencia.

En este punto, a mi parecer, casi se podría con las mismas nociones derrideanas justificar la

\footnotetext{
${ }^{34}$ Habermas, J., Modernidad: Un Proyecto Incompleto. En N. Casullo (comp.), El debate Modernidad Posmodernidad. Buenos Aires: Puntosur, 1989, pp.131-154.
} 
inevitable universalidad a la que según Habermas han de tender las proposiciones filosóficas. Todo enunciado que se quiere válido, se quiere como tal en tanto ha de podérselo reconocer en sucesivas ocasiones distintas a aquella en particular en la que se lo está usando. Puesto que los signos migran incesantemente en sucesivas remisiones y envíos, puesto que el juego de diferencias tiende al infinito en tanto no tiene cota predeterminada, todo lo dicho o escrito en el lenguaje es trascendencia de lo local, fuga y huida del presente, materialidad de signos que así nos muestran la posibilidad siempre abierta de su subsistencia más allá de las condiciones concretas y actuales en que los hacemos operar. La escritura y su juego infinito de diferencias despierta la sed de lo universal, de aquello que quiere viajar y trascender más allá de su actualidad concreta y circunscrita. Casi que tal pretensión de universalidad en tanto trascendencia de las condiciones locales (de tiempo y espacio) de un lenguaje actuado no puede, aunque se quiera, frenarse ni evitarse. Cierto es que en este juego interminable de envíos no nos acercamos nunca a una supuesta presencia plena de la verdad, el conocimiento, o el valor puro de la justicia o la igualdad, pero esto es algo que al parecer Habermas y buena parte de la conciencia pública filosófica tienen ya asumido sin reservas desde hace más tiempo de lo que Derrida supone.

Aunque Habermas es bastante lúcido al advertir que la filosofia del sujeto no se abandona por una única vía, mostrando que aquella escogida por las críticas heideggeriana y derrideana fracasan en este abandono, hay cierta precipitación cuando su teoría de la acción comunicativa se hace equivalente a la única alternativa posible para sostener en pie el proyecto ilustrado de la modernidad. No habría otra forma de recuperar valores como la justicia, la igualdad, la libertad, que no fuera sino por el expediente de la racionalización de la acción comunicativa ${ }^{35}$. Denegar la base racional, argumental y universal de los discursos filosóficos, y sobre todo de los éti$\cos$, equivale al parecer en Habermas a denegar cualquier ética posible. Me parece que este paso, en que se nos presenta como condición necesaria una cosa respecto de la otra, es el que requeriría cuando menos una examinación más acuciosa.

${ }^{35}$ Habermas, J., Escritos sobre Moralidad y Eticidad. Barcelona: Paidós, 1991.
Por otra parte, creo que Habermas minimiza hábilmente -tratando de esconder- los evidentes riesgos totalizantes que se asoman en la defensa de una ética universal de carácter racional, por más que ella sea situada en el consenso y el diálogo. El riesgo de pasar a llevar minorías marginales, o estadísticamente despreciables ante una gran mayoría en consenso, es un peligro ético y político lo suficientemente visible como para pretender soslayarlo reduciendo la cuestión de la universalidad a unas abstractas consideraciones de índole formal-pragmática, no queriendo ver que esta universalidad tiende de suyo a borrar diferencias y a dejarse utilizar por los poderes de turno. Por nuestra parte, podemos sospechar que este núcleo duro universalista presente en la ética discursiva habermasiana tiene su raíz finalmente no en el plano moral sino en el epistemológico, allí donde el autor no acepta ya constructivismos y se declara, aunque posterior al giro pragmático, como un realista. "Sí, soy un realista respecto a la cuestión epistemológica y un constructivista en cuestiones morales. (...) Estoy convencido de que en la práctica no podemos sino oponer un mundo de entidades independeintes de nuestra descripción; un mundo que es más o menos el mismo para todos". ${ }^{36}$

Si Habermas advierte sobre la necesidad de que los consensos y acuerdos sean tomados en el marco de comunicaciones libres de toda coacción e intereses particulares, es porque está reconociendo de entrada la fuerza y presencia de tales amenazas. Habermas expresa algo así como una verdad anhelante de constituirse en tal. Pero ese cuadro de comunicación libre en el que todos acordamos sin presiones de ningún tipo nuestros destinos como pueblo, tiene la inevitable semblanza de una ensoñación poco realista. Tal comunidad lingüística libre de coacciones supone agentes ideales casi evolucionados hasta el punto en que nos cuesta reconocernos en ellos. Sujetos capaces de suspender o dejar fuera de juego a voluntad sus pasiones, intereses personales, ansias de poder, rencores, envidias y todo tipo de 'desviaciones' que pudieren afectar el proceso crucial de la toma de acuerdos y decisiones en conjunto. Tal cosa no parece posible y aun todavía tal vez ni siquiera deseable como condición de toda ética. Tal como el mis-

${ }^{36}$ Habermas, J., La Ética del Discurso y la Cuestión de la Verdad. Buenos Aires: Paidós, 2004, p. 67. 


\section{ESCRITURA, PENSAMIENTO Y LENGUAJE: CONSIDERACIONES ACERCA DE UNA ÉTICA...}

mo Habermas se encarga de señalar, su ética discursiva es puramente formal tal como lo es la kantiana, en el sentido de que se plantea sólo en términos procedimentales de cómo es que deben hacerse las cosas, pero no especifica qué es lo que ha de hacerse ${ }^{37}$. Visto así, creo que también aquí entonces sería pertinente la réplica que otrora un pensador vitalista como Dilthey formulara frente a la filosofía kantiana, al decir que "por las venas del sujeto cognoscitivo kantiano no corre sangre verdadera". Pareciera que Habermas en la formalidad de la ética propuesta no dejara espacio para lo que tal vez de más humano tenga nuestra praxis social, la capacidad de ser tentados hacia la libre ruptura de aquello que nos obliga o norma.

\section{Referencias}

BARRIENTOS, J. P., El dilema de la ética: la ilusión neoilustrada o la renuncia posmoderna. En "Anuario de Postgrado", Facultad de Filosofia y Humanidades, Universidad de Chile, 2003, N 5, pp. 123-144.

CALLINICOS, A., Contra el Postmodernismo: Una crítica marxista. Bogotá: El Áncora Editores, 1993.

CULLER, J., Sobre la deconstrucción. Madrid: Cátedra, 1984.

DERRIDA, J., De la Gramatología. México: Siglo XXI editores, 1971.
DERRIDA, J., La escritura y la diferencia. Es raña: Anthropos, 1989.

DERRIDA, J., Márgenes de la Filosofia. Madrid: Cátedra, 1988.

DERRIDA, J., El tiempo de una tesis: Deconstrucción e implicaciones conceptuales. Barcelona: Proyecto A Ediciones, 1997.

ROJO, G., Diez tesis sobre la Crítica. Santiago: LOM Ediciones, 2001.

HABERMAS, J., El discurso filosófico de la Modernidad. Madrid: Taurus, 1989.

HABERMAS, J., Modernidad: Un Proyecto Incompleto. En N. Casullo (comp.), El debate Modernidad Posmodernidad. Buenos Aires: Puntosur, 1989, pp.131-154.

HABERMAS, J., Escritos sobre Moralidad y Eticidad. Barcelona: Paidós, 1991.

HABERMAS, J., Conciencia Moral y Acción Comunicativa. Barcelona: Península, 1991.

HABERMAS, J., La Ética del Discurso y la Cuestión de la Verdad. Buenos Aires: Paidós, 2004

KUHN, TH., La estructura de las revoluciones cientificas. México: FCE, 1971.

LYOTARD, J.-F., La condición posmoderna. Madrid: Cátedra, 1986.

PEÑALVER, P., La deconstrucción: escritura y filosofia. Barcelona: Montesinos, 1990.

RORTY, R., Contingencia, Ironía y Solidaridad. Barcelona: Paidós, 1996.

RORTY, R., Ensayos sobre Heidegger y otros pensadores contemporáneos. Barcelona: Paidós, 1993.

${ }^{37}$ Habermas, J., Conciencia Moral y Acción Comunicativa. Barcelona: Península, 1991. 